\title{
The effect of amidation on the behaviour of antimicrobial peptides
}

\author{
Manuela Mura ${ }^{2} \oplus \cdot J^{\prime}$ ianping Wang ${ }^{1} \cdot$ Yuhua Zhou $^{1} \cdot$ Marco Pinna $^{2} \cdot$ \\ Andrei V. Zvelindovsky ${ }^{2}$ - Sarah R. Dennison ${ }^{3,4} \cdot$ David A. Phoenix $^{4}$
}

Received: 27 March 2015 / Revised: 15 October 2015 / Accepted: 20 October 2015 / Published online: 8 January 2016

(C) The Author(s) 2016. This article is published with open access at Springerlink.com

\begin{abstract}
Aurein 2.6-COOH and aurein 3.1-COOH were studied along with their naturally occurring C-terminally amidated analogues. Circular dichroism (CD) and molecular dynamic (MD) simulations were used to study the effects of amidation on the interaction of antimicrobial peptides (AMPs) with lipid bilayers. CD measurements and MD analysis suggested that both peptide analogues were predominantly random coil and adopted low levels of $\alpha$-helical structure in solution $(<30 \%)$ and in the presence of a lipid bilayer the peptides formed a stable $\alpha$ -helical structure. In general, amidated analogues have a greater propensity than the non-amidated peptides to form a $\alpha$-helical structure. MD simulations predicted that aurein 2.6- $\mathrm{COOH}$ and aurein 3.1-CHOOH destabilised lipid bilayers from 1,2-dimyristoyl-sn-glycero-3-phosphocholine and 1,2-dimyristoyl-sn-glycero-3-phosphoserine via angled bilayer penetration. They also showed that aurein 2.6$\mathrm{CONH}_{2}$ and aurein 3.1-CONH${ }_{2}$ formed a helix horizontal to the plane of an asymmetric interface.
\end{abstract}

Electronic supplementary material The online version of this article (doi:10.1007/s00249-015-1094-x) contains supplementary material, which is available to authorized users.

Manuela Mura

mmura@lincoln.ac.uk

1 UCLan Biomedical Technology Limited (Shenzhen), Shenzhen Virtual University Park, Shenzhen 518057, People's Republic of China

2 Computational Physics Group, School of Mathematics and Physics, University of Lincoln, Brayford Pool, Lincoln LN6 7TS, UK

3 School of Pharmacy and Biomedical Science, University of Central Lancashire, Preston PR1 2HE, UK

4 School of Applied Science, London South Bank University, 103 Borough Road, London SE1 0AA, UK
Keywords Antimicrobial peptides · Membrane · Molecular dynamics $\cdot$ Secondary structure $\cdot$ Cooperative effect $\cdot$ Amino acid $\cdot$ Anticancer

\section{Introduction}

Antimicrobial peptides (AMPs) form a part of the innate immune system across eukaryotic organisms and have potent therapeutic activity against a wide spectrum of bacteria and fungi ( $\mathrm{Li}$ et al. 2012; Brandenburg et al. 2012; Dennison et al. 2005). However, the mechanism of antimicrobial action of these peptides has yet to be fully elucidated and remains the subject of continuous research (Phoenix et al. 2013; Fox 2013; Wimley and Hristova 2011; Yeaman and Yount 2003). It is generally accepted that the ability of AMPs to kill microorganisms depends upon their ability to target the membranes of these organisms (Huang and Huang 2010; Strömstedt et al. 2010). AMPs are usually short molecules of up to 50 amino acid residues and a number have been shown to penetrate the membrane in an oblique orientation between 30 and $60^{\circ}$. Therefore, the role of the peptide terminus may be crucial in the penetration behaviour (Dennison and Phoenix 2011b; Dennison et al. 2012a). For instance, it was shown that the change in the C-terminal of the AMPs can stabilise the secondary structure and enhance the affinity of the peptide towards the membrane (Cao et al. 2005; Ali et al. 2001; Dennison et al. 2009a, 2012a; Dennison and Phoenix 2011b).

For a number of these peptides, post-translational modifications are also essential for their antimicrobial activity and the most common of these structural modifications is carboxyamidation (Sforca et al. 2004; Shalev et al. 2002; Dennison and Phoenix 2011b, b). Recently, studies by Dennison et al. have shown that aurein 2.5 
(GLFDIVKKVVGAFGSL-CONH 2 ) has greater antimicrobial potency against Klebsiella pneumonia than its carboxylated C-terminal analogue (GLFDIVKKVVGAFGSL$\mathrm{COOH}$ ) (Dennison et al. 2012a).

Previous research has demonstrated that the peptide structure is crucial in the binding to target membranes. It has been proposed that the key driver for increased efficacy by amidation is due to enhanced helix stability at the membrane interface, which supports the observation that amidated peptide modelin-5- $\mathrm{CONH}_{2}$ exhibited a higher level of helicity in comparison to modelin-5-COOH (Dennison and Phoenix 2011b). In support of this observation other researchers such as Sforca et al. suggested that the reduced antibacterial activity of non-amidated peptides is caused not only by the decreased positive surface charge but also by the structural perturbation of the amphiphilic $\alpha$-helix, which affects its ability to disturb the cell membrane (Sforca et al. 2004). However, other researchers have shown that the $\mathrm{N}$-terminal pGlu and amidated C-terminal do not significantly influence the $\beta$-hairpin amphiphilic structure of Gomesin but are critical for Gomesin's antimicrobial activity (Machado et al. 2012).

Despite the large body of experimental work on the role of amidation in the membrane interaction of AMPs using a wide range of techniques, such as Nuclear magnetic resonance (NMR) (Haney and Vogel 2009), circular dichroism (CD) (Greenfield 1999), fluorescence (Bocchinfuso et al. 2011), and lipid monolayer analysis (Dennison et al. 2010), detailed understanding of the mechanism underpinning this role is not yet fully understood. In response, molecular dynamics (MD) provide detailed information at the molecular level into many biological systems, giving an insight into the mechanism of interaction of amidated AMPs with the membrane (Cheng et al. 2011; Chen et al. 2011).

For example, Wang et al. (2012) used MD simulations to show that in the presence of a mixed 1-palmitoyl,2oleoyl-sn-glycero-3-phosphocholine (POPC) and 1-palmitoyl-2-oleoyl-sn-glycero-3-phosphoglycerol (POPG) lipid bilayer (1:2), the C-terminus amidated CM15 peptide interacted more strongly with the bilayer than the zwitterionic POPC. Dennison and Phoenix (2011b) proposed that the mechanism for amidated peptide isoforms to interact with membranes may be similar to the mechanism for melittin pore formation proposed by van den Bogaart et al. (2008). This mechanism shows that the initial binding of peptide to the membrane competes with peptide insertion and the ability of the peptide to form pores. Irudyam et al. used a coarse-grained and atomistic MD approach to investigate the binding and reorientation of melittin to the POPC bilayer (Irudayam and Berkowitz 2012). These authors suggested that the stabilisation of the helix at the membrane interface increases the concentration of melittin bound to the membrane, enabling stable pore formation and hence the N-terminus of the peptide to reorientate. Researchers have shown that stabilising the helix at the membrane interface increases the local peptide concentration, which leads to pore formation, or carpeting of the outer leaflet, thereby causing bilayer disruption. In support of this suggestion Dos Santos Cabrera et al. (2008) undertook MD analysis on amidated and non-amidated decapeptide anoplin (ANP) in 2,2,2-trifluoroethanol (TFE)/water mixtures. The latter studies provided detailed MD information on the stability of the peptide isoforms, supporting previous findings that the amidated peptide had a more stable $\alpha$-helical conformation compared to the non-amidated isoforms (Dos Santos Cabrera et al. 2008).

Although MD has been used to gain insight into peptide/membrane interactions, an accurate, full atomistic MD investigation of the role played by amidated and nonamidated peptide is lacking. In the present work, analogues of aurein AMPs isolated from Australian Southern Bell frogs, Litoria aurea, were used to investigate the role of amidation in the mechanism of membrane interaction (Cheng et al. 2009). These peptides show activity against a broad range of micro-organisms (Apponyi et al. 2004) and tumour activity (Rozek et al. 2000). In this study, aurein 2.6 and 3.1 are used to investigate the role of amidation in the mechanism of membrane action with two model lipid bilayers, 1,2-dimyristoyl-sn-glycero-3-phosphocholine (DMPC) and 1,2-dimyristoyl-sn-glycero-3-phosphoserine (DMPS), which mimic the mammalian cell membrane. Generally, phosphatidylserine (PS) is found primarily in the inner leaflet while phosphatidylcholine (PC) is found in the outer leaflet. Here, MD and CD spectroscopy were used to investigate the membrane interactions of aurein peptides and these data were compared to corresponding analyses on C-terminally non-aminated isoforms of the peptide.

\section{Methods and materials}

\section{Materials}

1,2-Dimyristoyl-sn-glycero-3-phosphocholine (DMPC) and 1,2-dimyristoyl-sn-glycero-3-phosphoserine (DMPS) were obtained from Avanti Polar Lipids (Alabaster, AL, USA) and used without further modification. The peptide analogues of aurein peptides-aurein 2.6- $\mathrm{COOH}$ (GLFDIAKKVIGVIGSL-COOH), aurein 2.6- $\mathrm{CONH}_{2}$ (GLFDIAKKVIGVIGSL-CONH ${ }_{2}$ ), aurein 3.1-COOH (GLFDIVKKIAGHIAGSI-COOH), and aurein 3.1- $\mathrm{CONH}_{2}$ (GLFDIVKKIAGHIAGSI-CONH ${ }_{2}$ - - were synthesised by SevernBiotech (UK) by solid-state synthesis and purified by HPLC to purity greater than $>95 \%$. 2,2,2-Trifluoroethanol (TFE) and all other solvents and reagents were supplied by Fisher Scientific UK. 


\section{Circular dichroism measurements}

The CD spectrum was recorded on a J-815 spectropolarimeter (JASCO, UK) equipped with a Peltier temperature control unit maintained at $30{ }^{\circ} \mathrm{C}$ as previously described (Dennison et al. 2013). All CD experiments were undertaken using a 10-mm path-length cell over a $260-180-\mathrm{nm}$ wavelength range at a scan speed of $50 \mathrm{~nm} / \mathrm{min}, 1 \mathrm{~nm}$ band width, and a data pitch of $0.5 \mathrm{~nm}$. For all spectra acquired, ten scans per sample were performed and averaged, and the baseline acquired in the absence of peptide was subtracted. Samples were prepared by dissolving each peptide in phosphate-buffered saline (PBS, $\mathrm{pH}$ 7.5) and $100 \%$ TFE to give a final peptide concentration of $0.01 \mathrm{mg} \mathrm{ml}^{-1}$. CD structural analysis was also performed with aurein 2.6 and aurein 3.1 peptide isoforms in the presence of lipid. To obtain small lamellar vesicles (SUVs), a predetermined amount of dried $\left(5 \mathrm{mg} \mathrm{ml}^{-1}\right)$ DMPC and DMPS was dissolved in chloroform, evaporated under a nitrogen stream, and placed under a vacuum overnight. The lipid film was then rehydrated using PBS (pH 7.5) and sonicated for $1 \mathrm{~h}$ or until the solution was no longer turbid. Liposomes were then extruded 11 times through a $0.1-\mu \mathrm{m}$ polycarbonate filter using an Avanti polar lipid mini-extruder apparatus. Peptide/lipid samples were prepared by adding stock peptide solution to a measured volume of lipid suspension to obtain the desired peptide:lipid molar ratio (1:100) before thorough mixing. For secondary structure estimation, the percentage $\alpha$-helical content of the CD spectra was then estimated using the CDSSTR, CONTIN, and SELCON3 algorithm (protein reference set 3,4,7, SPI75 and smo 180) on the DichroWeb server (Whitmore and Wallace 2004, 2008; Whitmore et al. 2010).

\section{Computational method}

The amidation effects of three aurein 2.6 and aurein 3.1 in different environments including water, TFE, DMPC, and DMPS were simulated by MD simulations. The mechanism of interaction between each aurein analogue and $0.1 \mathrm{~mol} / \mathrm{l}$ aqueous solution, TFE, DMPC, or DMPS was examined. The aurein peptides were assembled as a canonical $\alpha$-helix using AMBER tools 1.5. All simulations were performed with the GROMACS software package (Van Der Spoel et al. 2005; Hess et al. 2008; Mura et al. 2013; Dennison et al. 2013). The GROMOS53a6 force field was used to model the peptides in the presence of TFE (Fioroni et al. 2000; Malde et al. 2011; Mura et al. 2013; Dennison et al. 2013). Water was represented by a simple point charge (SPC) (Van Der Spoel et al. 1998). The force field for DMPS and DMPC were based on GROMOS53a6 force fields taken from the literature: Poger and Mark (2010), Nesterenko and Ermakov (2013), Malde et al. (2011), and Kandt et al. (2010). All structures were equilibrated at room temperature in water (NVT and NPT simulations). Two configurations were considered: in one case the peptides were outside the lipid bilayer system with the helical axis parallel to the lipid bilayer surface while in the second case the peptides were inserted into the lipid bilayer with the helical axis parallel to the $Z$ direction and relaxed in accordance with the protocol in Kandt et al. (2010). In the first case the peptides were placed at a distance of $3 \mathrm{~nm}$ from the top leaflet of the lipid bilayer with its axis perpendicular to the lipid-water interface (Mura et al. 2013). The simulations were performed by solvating the box with the peptides or the peptide/lipid, and counter ions $\mathrm{Na}^{+}$and $\mathrm{CL}^{-}$were added to neutralise the systems (see Table 2). Each system was equilibrated at $310 \mathrm{~K}$ in the sequence minimisation, NVT, and NPT simulations. An equilibration run of 2-ns NVT and 2-ns NPT was undertaken for all systems with the position of the peptide restrained using harmonic restraints with a constant force of 1.0 $\mathrm{kJ}^{-1} \mathrm{~nm}^{-2}$ per atom (Tieleman 2012; Chen et al. 2011; Kukol 2009; Mura et al. 2013). The cutoff for both van der Waals and Coulombic interactions is $1.2 \mathrm{~nm}$. The particle mesh Ewald (PME) method was used in all simulations. The temperature was coupled for single groups with a constant time for the coupling of $0.1 \mathrm{ps}$ to $310 \mathrm{~K}$ using the Berendsen thermostat. A semi-isotropic Berendsen barostat was also used with a coupling time of 2.0 ps (Piggot et al. 2011; Kukol 2009; Mura et al. 2013; Dennison et al. 2013). Simulations were undertaken at constant temperature, pressure, and number of molecules. All simulations were undertaken with constraints on all bond lengths using the LINCS algorithm (Hess et al. 1997). Then 200-ns simulations were performed in the NPT ensemble using periodic boundary conditions. The components of each system are shown in Table 1 (Dennison et al. 2013).

We calculated the hydrogen bonds using the post-processing ghbond option in GROMACS. The cutoff angle is $30^{\circ}$ and cutoff distance $3.5 \AA$.

\section{Results}

\section{Amidation effects on the structure and stability of aurein peptides}

Amidation of the C-terminus of peptides may disturb the intramolecular hydrogen bonds (HBs) in peptides and in the intermolecular ones between peptides and the solvent molecules. Thus the driving force to form $\alpha$-helical or $\beta$ 
Table 1 Details of the MD simulations for aureins 2.6 (A 2.6) and aureins 3.1 (A 3.1)

\begin{tabular}{|c|c|c|c|}
\hline & Box size $(\mathrm{nm})$ & Water & Ions \\
\hline \multicolumn{4}{|c|}{ Water environment } \\
\hline \multicolumn{4}{|l|}{$\mathrm{CONH}_{2}$} \\
\hline A 2.6 & $8.0 \times 8.0 \times 8.0$ & 16,815 & $31 \mathrm{Na}^{+}: 34 \mathrm{Cl}^{-}$ \\
\hline A 3.1 & $8.0 \times 8.0 \times 8.0$ & 16,808 & $31 \mathrm{Na}^{+}: 34 \mathrm{Cl}^{-}$ \\
\hline \multicolumn{4}{|l|}{$\mathrm{COOH}$} \\
\hline A 2.6 & $7.0 \times 7.0 \times 7.0$ & 11,117 & $21 \mathrm{Na}^{+}: 24 \mathrm{Cl}^{-}$ \\
\hline \multirow[t]{2}{*}{ A 3.1} & $6.8 \times 6.8 \times 6.8$ & 10,180 & $19 \mathrm{Na}^{+}: 22 \mathrm{Cl}^{-}$ \\
\hline & Box size (nm) & TFE & Ions \\
\hline \multicolumn{4}{|c|}{ TFE environment } \\
\hline \multicolumn{4}{|l|}{$\mathrm{CONH}_{2}$} \\
\hline A 2.6 & $6.8 \times 6.8 \times 6.8$ & 2470 & $21 \mathrm{Na}^{+}: 24 \mathrm{Cl}^{-}$ \\
\hline A 3.1 & $6.8 \times 6.8 \times 6.8$ & 2503 & $2 \mathrm{Na}^{+}: 5 \mathrm{Cl}^{-}$ \\
\hline \multicolumn{4}{|l|}{$\mathrm{COOH}$} \\
\hline A 2.6 & $7.7 \times 6.8 \times 6.8$ & 1390 & $11 \mathrm{Na}^{+}: 14 \mathrm{Cl}^{-}$ \\
\hline \multirow[t]{2}{*}{ A 3.1} & $7.7 \times 6.8 \times 6.8$ & 1368 & $11 \mathrm{Na}^{+}: 14 \mathrm{Cl}^{-}$ \\
\hline & Box size (nm) & Water & Ions \\
\hline \multicolumn{4}{|c|}{ DMPC 128 lipids peptide outside } \\
\hline \multicolumn{4}{|c|}{$\mathrm{CONH}_{2}$} \\
\hline A 2.6 & $6.5 \times 6.5 \times 9.1$ & 7478 & $3 \mathrm{Cl}^{-}$ \\
\hline A 3.1 & $6.3 \times 6.3 \times 9.3$ & 7388 & $3 \mathrm{Cl}^{-}$ \\
\hline \multicolumn{4}{|l|}{$\mathrm{COOH}$} \\
\hline A 2.6 & $6.3 \times 6.3 \times 9.3$ & 7413 & $3 \mathrm{Cl}^{-}$ \\
\hline A 3.1 & $6.4 \times 6.4 \times 9.1$ & 7416 & $3 \mathrm{Cl}-$ \\
\hline \multicolumn{4}{|c|}{ DMPC 127 lipids peptide inside } \\
\hline \multicolumn{4}{|l|}{$\mathrm{CONH}_{2}$} \\
\hline A 2.6 & $6.5 \times 6.5 \times 9.5$ & 7981 & $3 \mathrm{Na}^{+}: 6 \mathrm{Cl}^{-}$ \\
\hline A 3.1 & $6.3 \times 6.3 \times 7.1$ & 4601 & $2 \mathrm{Na}^{+}: 5 \mathrm{Cl}^{-}$ \\
\hline \multicolumn{4}{|l|}{$\mathrm{COOH}$} \\
\hline A 2.6 & $6.4 \times 6.4 \times 9.0$ & 7138 & $3 \mathrm{Na}^{+}: 6 \mathrm{Cl}^{-}$ \\
\hline A3.1 & $6.4 \times 6.4 \times 7.0$ & 4602 & $2 \mathrm{Na}^{+}: 5 \mathrm{Cl}^{-}$ \\
\hline \multicolumn{4}{|c|}{ DMPS 128 lipids peptide outside } \\
\hline \multicolumn{4}{|l|}{$\mathrm{CONH}_{2}$} \\
\hline A 2.6 & $5.5 \times 5.5 \times 12.6$ & 8073 & $128 \mathrm{Na}^{+}: 3 \mathrm{Cl}^{-}$ \\
\hline A 3.1 & $5.5 \times 5.5 \times 12.4$ & 8066 & $128 \mathrm{Na}^{+}: 3 \mathrm{Cl}^{-}$ \\
\hline \multicolumn{4}{|l|}{$\mathrm{COOH}$} \\
\hline A 2.6 & $5.5 \times 5.5 \times 12.8$ & 8083 & $128 \mathrm{Na}^{+}: 3 \mathrm{Cl}^{-}$ \\
\hline A 3.1 & $5.5 \times 5.5 \times 12.3$ & 8065 & $128 \mathrm{Na}^{+}: 3 \mathrm{Cl}^{-}$ \\
\hline \multicolumn{4}{|c|}{ DMPS peptide inside } \\
\hline \multicolumn{4}{|l|}{$\mathrm{CONH}_{2}$} \\
\hline A 2.6 & $5.7 \times 5.7 \times 8.3$ & 4642 & $125 \mathrm{Na}^{+}: 2 \mathrm{Cl}^{-}$ \\
\hline A 3.1 & $5.7 \times 5.7 \times 9.8$ & 6346 & $128 \mathrm{Na}^{+}: 3 \mathrm{Cl}^{-}$ \\
\hline \multicolumn{4}{|l|}{$\mathrm{COOH}$} \\
\hline A 2.6 & $5.7 \times 5.7 \times 8.7$ & 5076 & $125 \mathrm{Na}^{+}: 2 \mathrm{Cl}^{-}$ \\
\hline A 3.1 & $5.8 \times 5.8 \times 9.3$ & 6630 & $127 \mathrm{Na}^{+}: 3 \mathrm{Cl}^{-}$ \\
\hline
\end{tabular}

-sheet structures can be varied. Previous studies have proposed that the secondary structures of AMPs are likely to be affected by amidation of the C-terminus (Dennison et al. 2013). Our investigation focuses on the peptide membrane interaction using experimental and computational techniques. 
Table 2 The CD and MD secondary structure of the aureins in different environments

The secondary structure in MD has been averaged over the last $50 \mathrm{~ns}$ of the simulations. Blue boxes ratio of $\alpha$-helix; red boxes ratio of $\beta$-sheet; the dash represents $100 \%$ random coil

\begin{tabular}{|c|c|c|c|c|}
\hline & \multicolumn{2}{|c|}{ A2.6-COOH } & \multicolumn{2}{|c|}{ A2.6- $\mathrm{CONH}_{2}$} \\
\hline & CD & MD & CD & MD \\
\hline Water & - & $29 \pm 5 \% \quad 9 \pm 7 \%$ & - & - \\
\hline TFE & $75 \pm 2 \%$ & $50 \pm 5 \%$ & $71 \pm 1 \%$ & $59 \pm 5 \%$ \\
\hline $\begin{array}{c}\text { Out DMPC } \\
\text { In DMPC }\end{array}$ & $49 \pm 4 \%$ & \begin{tabular}{c|c}
$28 \pm 4 \%$ & $12 \pm 5 \%$ \\
$58 \pm 2 \%$
\end{tabular} & $56 \pm 1 \%$ & $\begin{array}{c}31 \pm 2 \% \quad 11 \pm 3 \% \\
39 \pm 3 \%\end{array}$ \\
\hline $\begin{array}{c}\text { Out DMPS } \\
\text { In DMPS }\end{array}$ & $48.0 \pm 0.7 \%$ & $\begin{array}{l}28 \pm 2 \% \\
70 \pm 2 \%\end{array}$ & $56 \pm 2 \%$ & $\begin{array}{l}32 \pm 2 \% \\
68 \pm 3 \%\end{array}$ \\
\hline
\end{tabular}

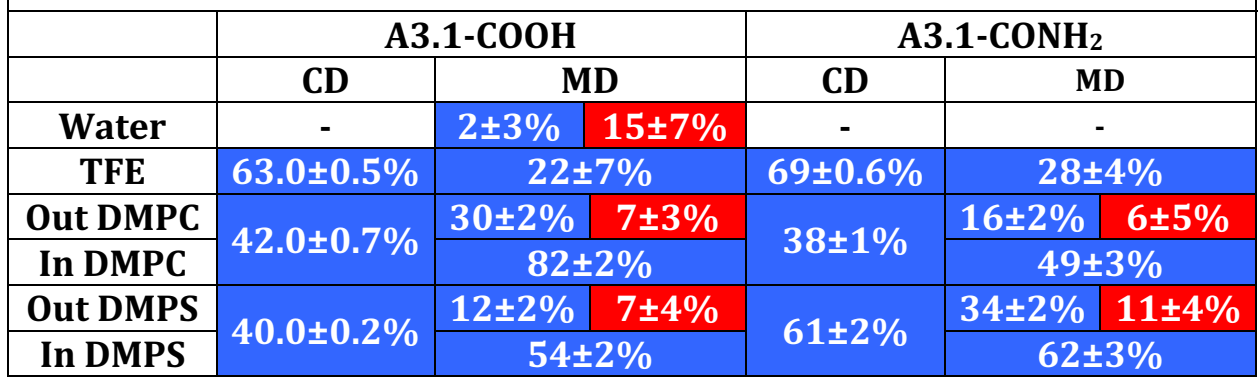
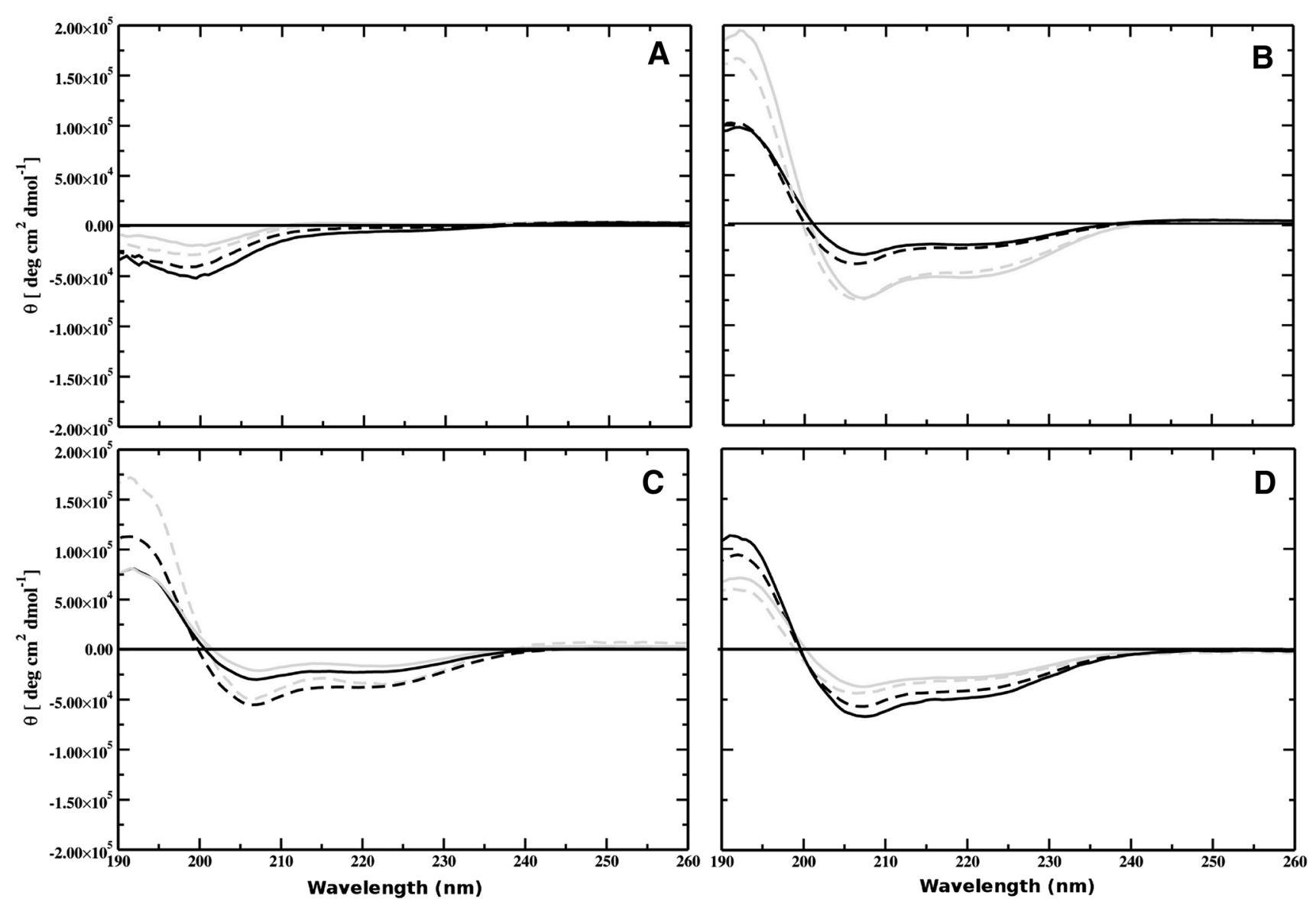

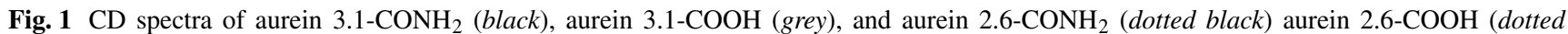
grey) in the presence of aqueous solution (a), TFE (b), DMPC (c), and DMPS (d) 


\section{Secondary structure analysis using $C D$}

In order to investigate the secondary structures of aurein 2.6 and aurein 3.1 isoforms in membrane mimetic environments, CD spectra were measured in PBS (pH 7.4), TFE, DMPC, and DMPS membranes (Fig. 1). Aurein 2.6 and 3.1 isoforms in PBS displayed spectral characteristics of a random coil structure (Fig. 1a). However, in a membrane environment each peptide studied adopted an $\alpha$-helical conformation displaying characteristic minima at 221-222 and 209-210 nm and a maximum at about $190 \mathrm{~nm}$ (Fig. 1b, c). The spectrum of aurein 2.6-COOH showed enhanced levels of helicity $(75 \%)$ in the presence of TFE compared to that of aurein 2.6- $\mathrm{CONH}_{2}(71 \%)$. In contrast, the spectrum of aurein 3.1- $\mathrm{CONH}_{2}(69 \%)$ showed an enhanced level of helicity compared to aurein 3.1-COOH (62\%), suggesting that amidation increased the propensity for the amidated peptide to form an $\alpha$-helical structure. Since it is widely accepted that cationic AMPs adopt an enhanced helical structure at a membrane-lipid interface (Dennison et al. 2013), CD experiments were undertaken in the presence of DMPC and DMPS lipid vesicles (Fig. 1c, d). CD spectroscopy spectral analysis in the presence of DMPC vesicles induced $56 \%$ helical content in aurein 2.6- $\mathrm{CONH}_{2}$ and $49 \%$ helicity in the case of aurein 2.6- $\mathrm{COOH}$, showing that amidation enhanced the helical content (Fig. 1c). However, for aurein 3.1 isoforms in the presence of DMPC vesicles $\mathrm{CD}$ analysis showed that both peptides were circa $40 \%$ helical (Table 2), indicating that amidation had no effect on these membranes. In contrast, in the presence of anionic DMPS vesicles (Fig. 1d), the spectrum of both amidated and non-amidated aureins showed a significant increase in helical content with aurein 2.6- $\mathrm{CONH}_{2}$ exhibiting a higher helical content (56\%) compared to aurein 2.6-COOH (48\%). Similarly, in the presence of DMPS vesicles aurein 3.1- $\mathrm{CONH}_{2}$ exhibited a higher helical content $(63 \%)$ compared to aurein 3.1-COOH (43\%).

\section{Secondary structure analysis using $M D$}

The secondary structure was analysed according to Joosten et al. (2011) and Kabsch and Sander (1983). The average aurein conformation was calculated over the last 50 ns of simulation since fewer conformational changes on the secondary structure were obseved. Aureins in a water environment exhibited an unstable secondary structure. However, for the non-amidated peptides the percentage of $\alpha$-helix or $\beta$-sheet was maintained (see Table 2). In the presence of TFE the aureins displayed a stable $\alpha$-helical conformation, which was slightly affected by the terminal section (see Table 2). Aureins 2.6 and 3.1 showed a different $\alpha$-helical conformation in the presence of TFE due to the difference in the number of amino acids ( 16 for aurein
2.6 and 17 for aurein 3.1) and in the sequence of the amino acids in the peptide. Aurein 2.6 has a stable $\alpha$-helical core fomed by ALA6-LYS7-LYS8, which is more stable than the core formed by aurein 3.1 (VAL6-LYS7-LYS8), which has a mutation of the amino acid ALA6 with VAL6. In both DMPC and DMPS membranes aurein 2.6- $\mathrm{CONH}_{2}$ displayed a stable $\alpha$-helical conformation (31 and $32 \%$ respectively). In DMPC the aureins also exhibited a stable $\beta$-sheet structure $(12 \%)$. Aurein $2.6-\mathrm{COOH}$ exhibited a lower percentage of $\beta$-sheet structure compared to the amidated peptide isoforms (28\% in DMPC and DMPS). The $\alpha$-helical conformation of aurein $3.1-\mathrm{CONH}_{2}$ is more stable in the presence of DMPS (24\%) than DMPC (16\%), whilst in the case of aurein 3.1-COOH the $\alpha$-helical conformation is more stable in the presence of DMPC (30\% against $12 \%$ ). For all aurein 3.1 isoforms a stable $\beta$-sheet conformation is also observed. In general peptides located in the membrane exhibited a greater percentage of $\alpha$-helical structure compared to peptides on the surface of the lipid bilayer. The highest percentage $(82 \%)$ of helical structure was observed for aurein 3.1-COOH inside the DMPC lipid bilayer (Table 2). In TFE the percentage helicity obtained computationally and experimentally showed a similar trend; however in the presence of lipid there were some differences in the values obtained.

\section{Dynamics properties of aureins in the presence of the lipid bilayer using MD.}

\section{Role of the C-terminus in the peptidellipid bilayer interaction}

In both peptides the presence of $\mathrm{NH}_{2}$ at the $\mathrm{C}$-terminus enables deeper penetration with the head groups of the DMPC lipid bilayer (Fig. 2). Here, the insertion of the N- (in red in Fig. 2) and C-terminus (in blue in Fig. 2) of the peptide is observed. In the case of non-amidated aureins the peptides interact with the lipid bilayer through the $\mathrm{N}$-terminal (in red in Fig. 2) residues favouring a tilted insertion (see supplementary information). Moreover, insertion of aurein peptide into the DMPS bilayer is observed in comparison to a DMPC bilayer. In contrast, a different behaviour is observed in the case of amidation on the C-terminus. Here, the $\mathrm{NH}_{2}$ group interacts with the head group of the DMPS lipid bilayer enhancing the interaction of the $\mathrm{N}$ - and C-terminus of the peptide with DMPS (see Fig. 2). The non-amidated aureins are situated in the water-lipid interface region with the $\mathrm{N}$-terminus and interact with the head groups of the lipid bilayer. Different residues in the amidated aureins are involved in the interaction with the lipid bilayer, influencing the mechanism of penetration. The $\mathrm{NH}_{2}$ at the C-terminus is influenced by the presence of $\mathrm{PO}_{4}$ groups in DMPC and $\mathrm{CO}_{2}$ in the DMPS lipid bilayer. In 
Fig. 2 Snapshot, after $200 \mathrm{ns,}$ of three aureins 2.6 and 3.1 starting outside the DMPC and DMPS membrane. The N-terminus (in red) and C-terminus (in blue) are highlighted in the graphic. The right-hand graphics in each panel show the partial densities of the components calculated in the last $50 \mathrm{~ns}$ of simulation: overall lipid density (solid black line), lipid head groups (dots), lipid tail groups (dashed line), phosphate atoms (brown line), the three peptides (blue line), peptide A (red line), peptide B (green line), and peptide $\mathrm{C}$ (orange line)

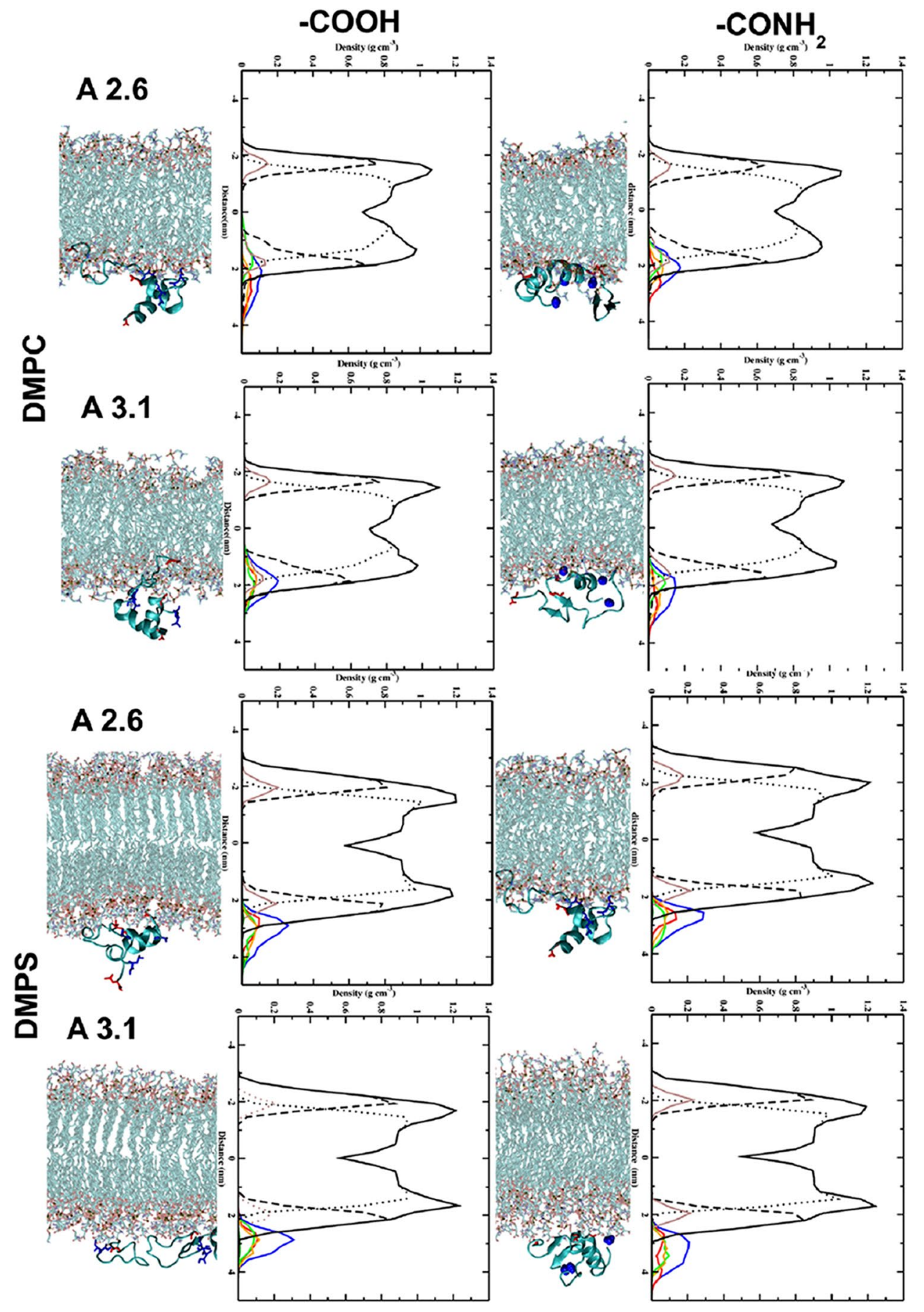

the second set of simulations the three peptides are inside the lipid bilayer. Inside the DMPC and DMPS bilayer the presence of $\mathrm{NH}_{2}$ at the C-terminus highlights that each single peptide interacts with the head groups of the DMPC lipid bilayer (Fig. 3). In contrast, in the case of aurein 2.6$\mathrm{COOH}$, the C-terminus interacts with the inner part of the head groups of the DMPC lipid bilayer showing increased mobility of the peptides inside the hydrophobic core of the phospholipid bilayer (Fig. 3). The peptides after 200 ns show a very stable secondary structure inside the lipid bilayer.

\section{Hydrogen bonds}

Hydrogen bond (HB) analysis was performed for interactions between the peptide, N-terminus, or peptide 
Fig. 3 Snapshot, after 200 ns, of three aureins 2.6 (A 2.6) and 3.1 (A 3.1) starting inside the DMPC and DMPS membrane. The $\mathrm{N}$-terminus (in red) and C-terminus (in blue) are highlighted in the graphic. The right-hand graphics in each panel show partial densities of the components calculated in the last $50 \mathrm{~ns}$ of simulation: overall lipid density (solid black line), lipid head groups (dots), lipid tail groups (dashed line), phosphate atoms (brown line), the three peptides (blue line), peptide A (red line), peptide $\mathrm{B}$ (green line), and peptide C (orange line)

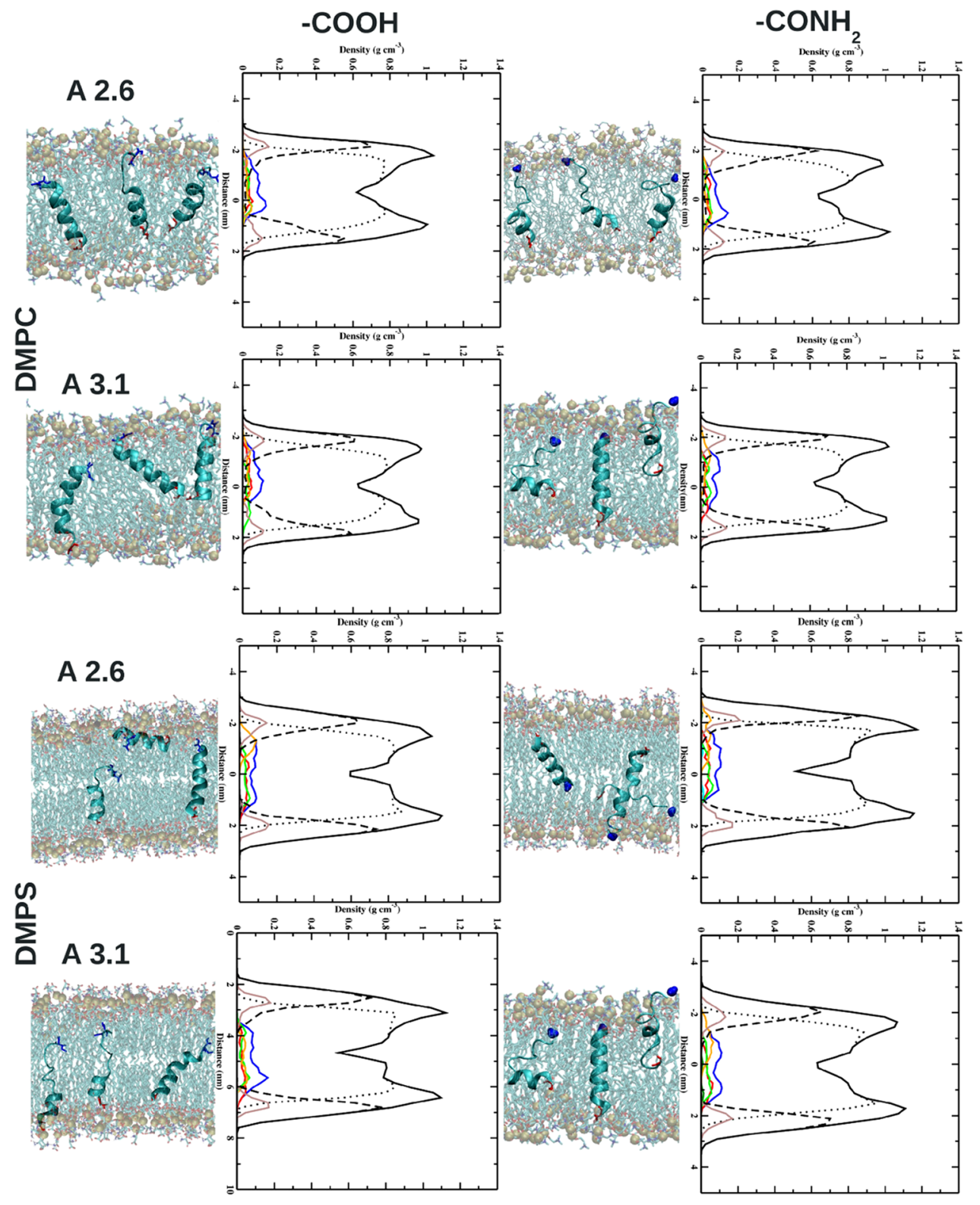

C-terminus (for the aureins outside the membrane) and the head groups of the membrane as a function of the simulation time. The number of $\mathrm{HBs}$ between the peptide and lipid bilayer increases with time as the peptide interacts more deeply with the lipid bilayer (Fig. 4). In the majority of cases after 50 ns circa 10 HBs are observed between the peptides and lipid bilayer. The number of HBs between the $\mathrm{C}$ - and $\mathrm{N}$-terminus and lipid bilayer depends on the presence of the $\mathrm{NH}_{2}$ group on the C-terminus. For carboxylate peptides the number of HBs between the terminus and lipid bilayer is strongly influenced by the lipid bilayer and bonding properties of the peptide sequence. Circa 2.5 $\mathrm{HBs}$ between the $\mathrm{N}$-terminus and lipid bilayer are observed for aurein 2.6-COOH in DMPC. The HBs between the
C-terminus and lipid bilayer are observed after $40 \mathrm{~ns}$ (2 HBs) (Fig. 4). Circa $1 \mathrm{HB}$ between the C-terminus and lipid bilayer is observed for aurein 2.6-COOH in DMPS. In contrast, HBs between the N-terminus and lipid bilayer are observed only at the beginning of the simulations (0-10 ns) and are very unstable. Circa $3 \mathrm{HBs}$ between the N-terminus and lipid bilayer are observed for aurein 3.1-COOH in DMPC. The HBs between the C-terminus and lipid bilayer are observed after 140 ns (2 HBs) (Fig. 4). Aurein 3.1$\mathrm{COOH}$ in DMPS shows a different trend compared to the previous peptides; circa 2 HBs between the N-terminus and lipid bilayer are observed during the simulations. While the HBs between the C-terminus and lipid bilayer are unstable with a relatively short-lived formation, circa $3 \mathrm{HBs}$ 
between the $\mathrm{C}$-terminus and lipid bilayer are observed after $20 \mathrm{~ns}$ for aurein 2.6- $\mathrm{CONH}_{2}$ in DMPC, while there are no HBs between the N-terminus and lipid bilayer. Aurein 2.6$\mathrm{CONH}_{2}$ in DMPS has an increased number of HBs (circa 3 ) between the C-terminus and lipid bilayer compared to aurein 2.6-COOH. HBs between the N-terminus and lipid bilayer are also more stable during the simulation time (circa 2.5 HBs) (Fig. 4). Circa two HBs between the N-terminus and lipid bilayer are observed up to $70 \mathrm{~ns}$ aurein 3.1$\mathrm{CONH}_{2}$ in DMPC. The HBs between the C-terminus and lipid bilayer are observed after 95 ns (circa 2 HBs). Circa 3 HBs between the $\mathrm{N}$-terminus and lipid bilayer are observed during the simulations for aurein 3.1- $\mathrm{CONH}_{2}$ in DMPS. While the HBs between the C-terminus and lipid bilayer (circa 2) are observed after $100 \mathrm{~ns}$, there is no significant difference in the formation of HBs between the peptides and lipid bilayer. The presence of $\mathrm{NH}_{2}$ at the terminus of the peptide showed a larger number of HBs between the peptide C-terminus and lipid bilayer (red line in Fig. 4).

\section{Discussion}

A wide range of structural conformations has been displayed by AMPs (Maget-Dana 1999) and the ability of an AMP to interact with a target membrane not only depends upon the peptide structural characteristics but also the membrane target (Nguyen et al. 2011). The mechanism of AMP interaction is dependent on the membrane environment and currently no single model can explain the mechanism of action. However, it is generally accepted that the targeting and binding of the peptide to the membrane are via electrostatic interactions between the cationic regions of the peptide and negatively charged moieties occurring in membranes of these target cells (Dennison et al. 2007). Once associated with the membrane, one factor that has been identified as important for activity is the stability of the secondary structure prior to membrane penetration (Giangaspero et al. 2001; Dennison et al. 2012b, a). Cabrera et al. stated that C-terminal amidation is important for both the helix stability and lytic activity of peptides (dos Santos Cabrera et al. 2004). CD and MD structural studies indicated that both aurein isoforms were unstructured in solution (Fig. 1; Table 2) and then fold to form an $\alpha$-helical conformation in the presence of a lipid interface (Dennison et al. 2013).

Many studies have shown that the antimicrobial activity of AMPs is related to the positive charge of peptides (Giangaspero et al. 2001; Dennison et al. 2009b, 2003, 2005; Benko-Iseppon et al. 2010). Amidated peptides have a higher positive charge than the corresponding nonamidated peptide, which may be the reason why some are more active. The greater net charge on aurein $2.6-\mathrm{CONH}_{2}$ and aurein 3.1- $\mathrm{CONH}_{2}$ compared to aurein 2.6- $\mathrm{COOH}$ and aurein 3.1-COOH would therefore be predicted to enhance the membrane association. To obtain further information on the mode of action of aurein 2.6 and aurein 3.1 analogues, $\mathrm{CD}$ experiments were performed in the presence of TFE. Aurein 2.6- $\mathrm{CONH}_{2}$ and aurein $3.1-\mathrm{CONH}_{2}$ were seen to adopt the $\alpha$-helical structure in the presence of TFE [71 and $61 \% \alpha$-helix respectively (Table 2)] and show a greater helicity percentage compared to the carboxyl-free C-terminus. The same behaviour has been confirmed by MD simulations, which showed that the peptides exhibited a stable conformation (Table 2). In the presence of lipids $\mathrm{CD}$ analysis showed that the aurein 2.6- $\mathrm{CONH}_{2}$ possesses a greater helicity compared to aurein 2.6- $\mathrm{COOH}$ supported by MD analysis. Furthermore, in DMPC, the aurein 2.6 can bind the stabilising helix at the membrane interface (Table 2), which leads to different modes of interaction and membrane binding compared to aurein 3.1.

Peptide binding and partitioning into a membrane are affected by the ability of an AMP to alter the lipid polymorphism of a membrane (Epand 1997). A number of factors determine the lipid polymorphism of a membrane, for example the location of the peptide in a membrane, the presence of amino acids, which contain several C-C bonds in the side chain such as LYS, and physiochemical characteristics such as charge and amphiphilicity, with evidence to show that hydrophobicity determines the level of membrane partitioning. The MD analysis in Fig. 2 shows that for aurein 2.6-COOH and aurein 3.1-COOH in the presence of a DMPC and DMPS bilayer, the peptides orientate horizontally to the water-lipid interface, allowing shallow penetration into the hydrophobic core of the lipid interior. Here the LYS amino acids, which are centrally located in the peptide, are interacting with the head groups of the lipid bilayer forming HBs with the lipid bilayer. This horizontal orientation of the peptide would lead to lipid head groups being pushed aside by the peptide and hence forcing a gap in the membrane hydrophobic region. This result is comparable to other AMPs, which may utilise a carpet or toroidal pore-type mechanism (Sato and Feix 2006; Hoskin and Ramamoorthy 2008; Fernandez et al. 2012). The amidated C-terminus of the peptide can also form a larger number of HBs in comparison with carboxyl peptides in all cases. This affects the secondary structures and activities of the amidated and non-amidated aurein 2.6 and aurein 3.1 at the water-lipid interface.

The amidated peptides tilt their helices (Fig. 2) and hence the lipids distort their acyl chains by compressing the lipids to match the peptide molecular architecture or by stretching of the acyl chains (Ramadurai et al. 2010). Ramadurai et al. showed that the degree of the tilt is due to positive and negative mismatch due to the presence of snorkelling Lys residues. In turn this leads to a curvature 


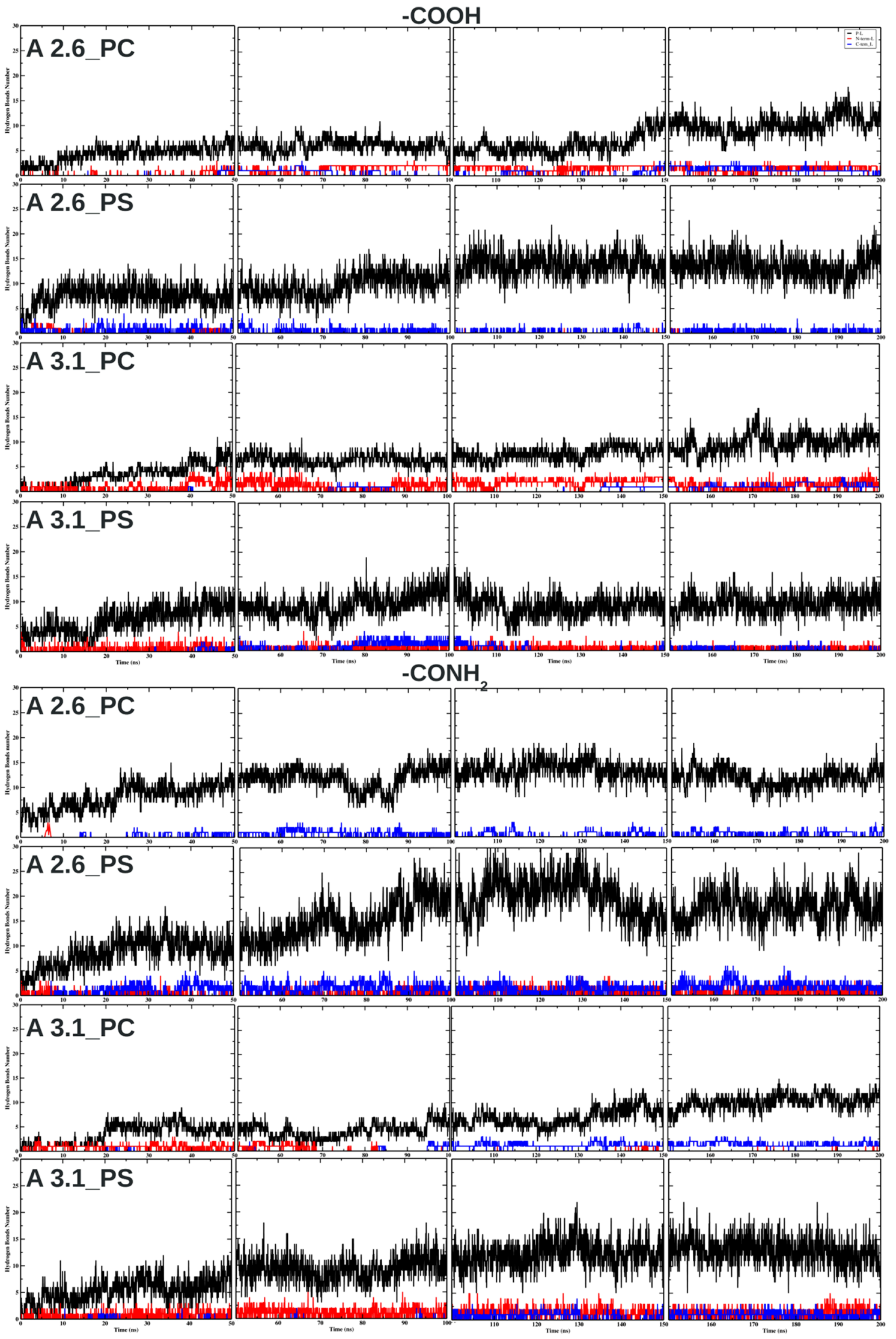


\Fig. 4 The hydrogen bond number vs. time for three aureins 2.6 and aureins 3.1 (when the peptides are starting from the configuration outside the lipid bilayer), between peptides and lipid molecules $(P-L)$, between $\mathrm{C}$-terminal groups of the peptide $\left(\mathrm{COOH}\right.$ or $\mathrm{CONH}_{2}$ ) and lipid bilayer (C-term-L), and between the $\mathrm{N}$-terminal groups of the peptide and lipid bilayer (N-term-L)

around the peptide in the bilayer leading to membrane destabilisation (Ramadurai et al. 2010). This oblique orientation mechanism has been proposed for other aurein amidated peptides, such as aurein 1.2 (Marcotte et al. 2003) and aurein 2.3 (Mura et al. 2013), which have been shown to insert into the membrane with a shallow angle between $30^{\circ}$ and $60^{\circ}$ leading to membrane destabilisation.

In conclusion, our analysis highlights how the mechanism of interaction between the peptide and lipid bilayer is dependent on whether the peptide is amidated at the C-terminus. The configuration of the peptide inside the lipid bilayer also throws light on the interaction between the peptide and bilayer component. When the peptides and the lipid bilayer are in close contact, HBs are formed between the carboxyl terminal and head groups of lipid molecules, which contribute to the different behaviour of peptides at the water-lipid interface.

Aurein 2.6- $\mathrm{CONH}_{2}$ shows a contribution of $\alpha$-helical conformation larger than aurein 2.6- $\mathrm{COOH}$ in both the membranes while aurein 3.1- $\mathrm{CONH}_{2}$ shows a larger $\alpha$ -helical conformation only in the presence of the DMPC membrane. These results are in agreement with $\mathrm{CD}$ experiments. When the peptides are inside the membrane, the LYS interacts with the head group of the lipid bilayer, staying anchored to the hydrophilic interface region (Fig. 5). This behaviour of the LYS residue creates a perturbation on the membrane allowing the penetration of water molecules.
Fig. 5 Bottom Interaction of the lysine residue (in blue) of aurein 2.6 with the phosphate atoms (brown) of the DMPC lipid bilayer at $200 \mathrm{~ns}$. Top Magnified image of one $\alpha$-helical structure

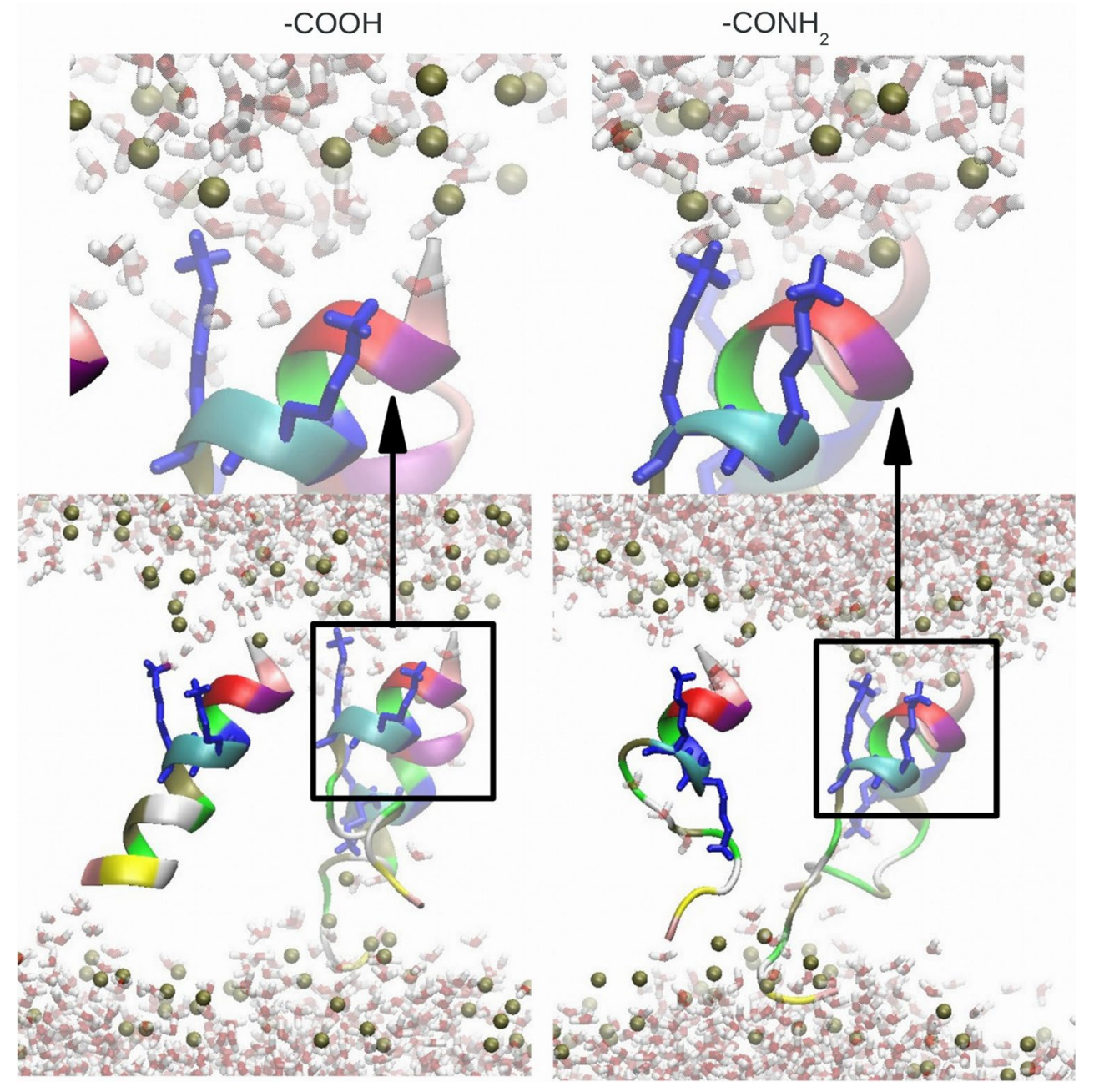


Acknowledgments MM thanks the Volkswagen Foundation (Germany) for the financial support (Ref.: 83932). All simulations were carried out at the UCLan High Performance Computing Facilities.

Open Access This article is distributed under the terms of the Creative Commons Attribution 4.0 International License (http://creativecommons.org/licenses/by/4.0/), which permits unrestricted use, distribution, and reproduction in any medium, provided you give appropriate credit to the original author(s) and the source, provide a link to the Creative Commons license, and indicate if changes were made.

\section{References}

Ali MF, Soto A, Knoop FC, Conlon J (2001) Antimicrobial peptides isolated from skin secretions of the diploid frog, Xenopus tropicalis (Pipidae). Biochim Biophys Acta (BBA) 1550(1):81-89

Apponyi MA, Pukala TL, Brinkworth CS, Maselli VM, Bowie JH, Tyler MJ, Booker GW, Wallace JC, Carver JA, Separovic F (2004) Host-defence peptides of australian anurans: structure, mechanism of action and evolutionary significance. Peptides 25:1035-1054

Benko-Iseppon AM, Galdino SL, Calsa TJ, Kido EA, Tossi A, Belarmino LC, Crovella S (2010) Overview on plant antimicrobial peptides. Curr Protein Pept Sci 11:181-188

Bocchinfuso G, Bobone S, Mazzuca C, Palleschi A, Stella L (2011) Fluorescence spectroscopy and molecular dynamics simulations in studies on the mechanism of membrane destabilization by antimicrobial peptides. Cell Mol Life Sci 68(13):2281-2301

Brandenburg L, Merres J, Albrecht LJ, Varoga D, Pufe T (2012) Antimicrobial peptides: multifunctional drugs for different applications. Polymers 4:539-560

Cao W, Zhou Y, Ma Y, Luo Q, Wei D (2005) Expression and purification of antimicrobial peptide adenoregulin with C-amidated terminus in Escherichia coli. Protein Expr Purif 40(2):404-410

Chen R, Mark AE (2011) The effect of membrane curvature on the conformation of antimicrobial peptides: implication for binding and the mechanism of action. Eur Biophys J 40:545-553

Cheng JTJ, Hale JD, Elliott M, Hancock R, Straus S (2011) The importance of bacterial membrane composition in the structure and function of aurein 2.2 and selected variants. Biochim Biophys Acta 1808:622-633

Cheng JTJ, Hale JD, Elliott M, Hancock REW, Straus SK (2009) Effect of membrane composition on antimicrobial peptides aurein 2.2 and 2.3 from Australian southern bell frogs. Biophys J 96(2):552-565

Dennison S, Wallace J, Harris F, Phoenix D (2005) Relationships between the physiochemical properties, microbial specificity and antimicrobial activity of helical antimicrobial peptides: a statistical investigation. Curr Top Pept Protein Res 7:43-88

Dennison SD, Harris F, Bhatt T, Singh J, Phoenix DA (2009a) The effect of c-terminal amidation on the efficacy and selectivity of the antimicrobial peptides. Mol Cell Biochem 332:43-50

Dennison SR, Harris F, Bhatt T, Singh J, Phoenix DA (2009b) The effect of C-terminal amidation on the efficacy and selectivity of antimicrobial and anticancer peptides. Mol Cell Biochem 332(1-2):43-50

Dennison SR, Harris F, Mura M, Morton LHG (2013) A novel form of bacterial resistance to the action of eukaryotic host defence peptides, the use of a lipid receptor. Biochemistry 52:6021-6029

Dennison SR, Harris F, Phoenix DA (2003) Factors determining the efficacy of alpha-helical antimicrobial peptides. Protein Pept Lett 10:497-502
Dennison SR, Harris F, Phoenix DA (2007) The interactions of aurein 1.2 with cancer cell membranes. Biophys Chem 127:78-83

Dennison SR, Harris F, Phoenix DA (2010) A Langmuir approach using on monolayer interactions to investigate surface active peptides. Protein Pept Lett 17:1363-1375

Dennison SR, Morton LHG, Phoenix DA (2012a) Effect of amidation on the antimicrobial peptide aurein 2.5 from Australian southern bell frogs. Protein Pept Lett 19(6):586-591

Dennison SR, Morton LHG, Phoenix DA (2012b) Role of molecular architecture on the relative efficacy of aurein 2.5 and modelin 5 . Biochim Biophys Biomembr 1818(9):2094-2102. doi:10.1016/j. bbamem.2012.05.015

Dennison SR, Phoenix DA (2011a) Effect of cholesterol on the membrane interaction of modelin-5 isoforms. Biochemistry 50(50):10898-10909

Dennison SR, Phoenix DA (2011b) Influence of C-terminal amidation on the efficacy of modelin-5. Biochemistry 50(9):1514-1523. doi:10.1021/bi101687t

Dennison SR, Wallace J, Harris F, Phoenix DA (2005) Amphiphilic alpha-helical antimicrobial peptides and their structure/function relationships. Protein Pept Lett 12:31-39

Dos Santos Cabrera MP, Arcisio-Miranda M, Broggio Costa ST, Konno K, Ruggiero JR, Procopio J, Ruggiero Neto J (2008) Study of the mechanism of action of anoplin, a helical antimicrobial decapeptide with ion channel-like activity, and the role of the amidated c-terminus. J Pept Sci 14:661-669

dos Santos Cabrera MP, de Souza BM, Fontana R, Konno K, Palma MS, de Azevedo WFJ, Neto JR (2004) Conformation and lytic activity of eumenine mastoparan: a new antimicrobial peptide from wasp venom. J Pept Res 64:95-103

Epand RM (1997) Modulation of lipid polymorphism by peptides. In: Richard ME (ed) Current topics in membranes, Chap 6. Academic Press, pp 237-252

Fernandez DI, Le Brun AP, Whitwell T, Sani MA, James M, Separovic $F(2012)$ The antimicrobial peptide aurein 1.2 disrupts model membranes via the carpet mechanism. Phys Chem Chem Phys 14:15739-15751

Fioroni M, Burger K, Mark AE, Roccatano D (2000) A new 2,2,2-trifluoroethanol model for molecular dynamics simulations. J Phys Chem B 104(51):12347-12354

Fox JL (2013) Antimicrobial peptides stage a comeback. Nat Biotechnol 31:379-382

Giangaspero A, Sandri L, Tossi A (2001) Amphipathic alpha helical antimicrobial peptides. Eur J Biochem 268:5589-5600

Greenfield NJ (1999) Applications of circular dichroism in protein and peptide analysis. Trends Anal Chem 18:236-244

Haney EF, Vogel HJ (2009) NMR of antimicrobial peptides. In: Annual reports on NMR spectroscopy, Chap 1. Academic Press, pp 1-51

Hess B, Bekker H, Berendsen HJC, Fraaije JGEM (1997) Lincs: a linear constraint solver for molecular simulations. J Comput Chem 18:1463-1472

Hess B, Kutzner C, van der Spoel D, Lindahl E (2008) GROMACS 4: algorithms for highly efficient, load-balanced, and scalable molecular simulation. J Chem Theory Comput 4(3):435-447

Hoskin DW, Ramamoorthy A (2008) Studies on anticancer activities of antimicrobial peptides. Biochim Biophys Acta 1778:357-375

Huang Y, Huang J, Chen Y (2010) Alpha-helical cationic antimicrobial peptides: relationships of structure and function. Protein Cell 1:143-152

Irudayam SJ, Berkowitz ML (2012) Binding and reorientation of melittin in a popc bilayer: computer simulations. Biochim Biophys Acta 1818:2975-2981

Joosten R, Te Beek TAH, Krieger E, Hekkelman M, Hooft RWW, Schneider R, Sander C, Vriend G (2011) A series of pdb related databases for everyday needs. Nucleic Acids Res 39:D411-D419 
Kabsch W, Sander C (1983) Dictionary of protein secondary structure: pattern recognition of hydrogen-bonded and geometrical features. Biopolymers 22:2577-2637

Kandt C, Ash WL, Tieleman DP (2010) Setting up and running molecular dynamics simulations of membrane proteins. Struct Biol Membr Proteins 41:475-488

Kukol A (2009) Lipid models for united-atom molecular dynamics simulations of proteins. J Chem Theory Comput 5(3):615-626

Li Y, Xiang Q, Zhang Q, Huang Y, Su Z (2012) Overview on the recent study of antimicrobial peptides: origins, functions, relative mechanisms and application. Peptides 37:207-215

Machado A, Fazio MA, Miranda A, Daffre S, Teresa Machini M (2012) Synthesis and properties of cyclic gomesin and analogues. J Pept Sci 18(9):588-598

Maget-Dana R (1999) The monolayer technique: a potent tool for studying the interfacial properties of antimicrobial and membrane-lytic peptides and their interactions with lipid membranes. Biochim Biophys Acta 1462:109-140

Malde AK, Zuo L, Breeze M, Stroet M, Poger D, Nair P, Oostenbrink C, Mark AE (2011) An automated force field topology builder (atb) and repository version 1.0. J Chem Theory Comput 7(12):4026-4037

Marcotte I, Wegener KL, Lam YH, Chia BC, de Planque MR, Bowie JH, Auger M, Separovic F (2003) Interaction of antimicrobial peptides from Australian amphibians with lipid membranes. Chem Phys Lipids 122:107-120

Mura M, Dennison SR, Zvelindovsky AV, Phoenix DA (2013) Aurein 2.3 functionality is supported by oblique orientated $\alpha$ -helical formation. Biochim Biophys Acta (BBA) Biomembr 1828(2):586-594

Nesterenko AM, Ermakov Y (2013) Molecular-dynamic simulation of phospholipid bilayers: Ion distribution at the surface of neutral and charged bilayer in the liquid crystalline state. Biochem Mosc Suppl Ser A 6:320-328

Nguyen LT, Haney EF, Vogel HJ (2011) The expanding scope of antimicrobial peptide structures and their modes of action. Trends Biotechnol 29(9):464-472

Phoenix DA, Dennison SR, Harris F (2013) Antimicrobial peptides. Wiley, London

Piggot TJ, Holdbrook DA, Khalid S (2011) Electroporation of the E. coli and $S$. aureus membranes: molecular dynamics simulations of complex bacterial membranes. J Phys Chem B 115(45):13381-13388

Poger D, Mark AE (2010) On the validation of molecular dynamics simulations of saturated and cis-monounsaturated phosphatidylcholine lipid bilayers: a comparison with experiment. J Chem Theory Comput 6(1):325-336

Ramadurai S, Holt A, Schafer LV, Krasnikov VV, Rijkers DT, Marrink SJ, Killian JA, Poolman B (2010) Influence of hydrophobic mismatch and amino acid composition on the lateral diffusion of transmembrane peptides. Biophys J 99:1447-1454
Rozek T, Wegener KL, Bowie JH, Olver IN, Carver JA, Wallace JC, Tyler MJ (2000) The antibiotic and anticancer active aurein peptides from the Australian bell drogs Litoria aurea and Litoria raniformis. Eur J Biochem 267(17):5330-5341

Sato H, Feix JB (2006) Peptide-membrane interactions and mechanisms of membrane destruction by amphipathic alpha-helical antimicrobial peptides. Biochim Biophys Acta 1758:1245-1256

Sforca M, Oyama S, Canduri F, Lorenzi C, Pertinhez T, Konno K, Souza B, Palma N, Neto J, Azevedo W, Spisni A (2004) How C-terminal carboxyamidation alters the biological activity of peptides from the venom of the eumenine solitary wasp. Biochemistry 43(19):5608-5617

Shalev DE, Mor A, Kustanovich I (2002) Structural consequences of carboxyamidation of dermaseptin s3. Biochemistry 41:7312-7317

van der Spoel D, van Maaren PJ, Berendsen HJC (1998) A systematic study of water models for molecular simulation: derivation of water models optimized for use with a reaction field. J Chem Phys 108:10220-10230

Van Der Spoel D, Lindahl E, Hess B, Groenhof G, Mark A, Berendsen HJC (2005) GROMACS: fast, flexible, and free. J Comput Chem 26(16):1701-1718

Strömstedt AA, Ringstad L, Schmidtchen A, Malmsten M (2010) Interaction between amphiphilic peptides and phospholipid membranes. Curr Opin Colloid Interface Sci 15:467-478

Tieleman DP (2012) Computational methods to model membrane dynamics, vol 5. Membrane dynamics. Academic Press, University of Virginia, VA, USA

van den Bogaart G, Guzmán JV, Mika JT, Poolman B (2008) On the mechanism of pore formation by melittin. J Biol Chem 283:33854-33857

Wang Y, Schlamadinger DE, Kim JE, McCammon JA (2012) Comparative molecular dynamics simulations of the antimicrobial peptide CM15 in model lipid bilayers. Biochim Biophys Acta 1818(5):1402-1409

Whitmore L, Wallace BA (2004) Dichroweb, an online server for protein secondary structure analyses from circular dichroism spectroscopic data. Nucleic Acids Res 32:W668-673

Whitmore L, Wallace BA (2008) Protein secondary structure analyses from circular dichroism spectroscopy: methods and reference databases. Biopolymer 89:392-400

Whitmore L, Woollett B, Miles AJ, Janes RW, Wallace BA (2010) The protein circular dichroism data bank, a web-based site for access to circular dichroism spectroscopic data. Structure 18:1267-1269

Wimley WC, Hristova K (2011) Antimicrobial peptides: successes, challenges and unanswered question. J Membr Biol 239:27-34

Yeaman M, Yount N (2003) Mechanism of antimicrobial peptide action and resistance. Pharmacol Rev 55:27-55 